\title{
Implementation and Evaluation of a Workshop on Patient Counseling about Antidiabetic Medications for Final-Year Pharmacy Students
}

\author{
Maram Gamal Katoue ${ }^{a}$ Asmaa Al Haqan ${ }^{b}$ \\ Departments of a Pharmacology and Therapeutics, and b Pharmacy Practice, Faculty of Pharmacy, \\ Health Sciences Centre, Kuwait University, Jabriya, Kuwait
}

\section{Key Words}

Pharmacist · Counseling · Antidiabetic medications ·

Diabetes

\begin{abstract}
Objective: To implement an interactive workshop for finalyear pharmacy students on patient counseling about antidiabetic medications and to assess its impact on knowledge and self-reported confidence of students in counseling. Subjects and Methods: The workshop was organized for all final-year pharmacy students $(n=27)$ during the academic year 2011-2012. It included various teaching and learning activities: interactive lectures, group work and role-playing. Pre-/postworkshop questionnaires were used to assess the impact of the workshop on students' knowledge about medications and attitudes to patient counseling, respectively. The workshop and the teaching activities were evaluated using an evaluation sheet. Data were analyzed using SPSS version 17. Paired Student's t test was used to compare the results of pre-/postintervention instruments. Statistical significance was accepted at a $p$ value of <0.05. Results: The mean \pm standard deviation of the pre- and postworkshop knowledge questionnaire scores were $47.9 \pm 17.6 \%$ and $70.7 \pm 18.6 \%$, respectively ( $p<0.05$ ), indicating that the workshop significantly improved students' knowledge
\end{abstract}

\begin{tabular}{ll}
\hline KARGER & $\begin{array}{l}\text { ( } 2013 \text { S. Karger AG, Basel } \\
1011-7571 / 13 / 0225-0489 \$ 38.00 / 0 \quad \text { Karger }\end{array}$ \\
E-Mail karger@karger.com & $\begin{array}{l}\text { This is an Open Access article licensed under the terms of the } \\
\text { www.karger.com/mpp }\end{array}$ \\
& $\begin{array}{l}\text { Creative Commons Attribution-NonCommercial 3.0 Un- } \\
\text { ported license (CC BY-NC) (www.karger.com/OA-license), } \\
\text { applicable to the online version of the article only. Distribu- } \\
\text { tion permitted for non-commercial purposes only. }\end{array}$
\end{tabular}

about antidiabetic medications. It also had significant effects on students' self-reported confidence in communicating effectively with patients and counseling them on antidiabetic medications. All participants strongly agreed that the workshop was very useful. The case discussion in small groups was ranked as the most preferred learning method by the students. Conclusion: This workshop was successful in improving knowledge and self-reported confidence of pharmacy students in counseling patients about antidiabetic medications. Adapting the use of engaging teaching methods allowed the students to become active, independent and self-directed learners and thus enhanced their confidence in providing pharmaceutical care to patients.

Copyright $\odot 2013$ S. Karger AG, Basel

\section{Introduction}

The prevalence of diabetes mellitus is rapidly rising worldwide [1]. This epidemic represents a significant health problem that necessitates active collaboration of all healthcare professionals to provide optimal patient care. There is substantial evidence to support the benefits of using a multidisciplinary approach to the delivery of diabetes care [2, 3]. Different healthcare providers can work together in a team to optimize patient management and outcomes [4].

Maram Gamal Katoue

Department of Pharmacology and Therapeutics

Faculty of Pharmacy, Kuwait University

P.O. Box 24923, Safat 13110 (Kuwait)

E-Mail maramk@hsc.edu.kw 
In view of the increasing number of treatment options available for diabetes, pharmacists can contribute to patient care by optimizing drug therapy [5]. One of their integral professional responsibilities is to educate patients regarding the proper and safe use of their medications. Beneficial effects of pharmacist interventions on patients with diabetes have been reported in several studies $[2,5$, 6]. Pharmacist-provided diabetes care and education have been found to enhance patients' adherence to their medications and preventative care measures, resulting in improved clinical outcomes [2,7]. These interventions also proved to reduce total costs related to diabetes care $[5,6]$.

In modern pharmacy education, pharmacy students learn about pharmaceutical care, which is defined as the responsible provision of pharmacotherapy for the purpose of achieving definite outcomes that improve the quality of life of patients [8]. Patient counseling regarding their therapy represents an essential component of pharmaceutical care $[9,10]$. It involves the provision of medication-related information to the patient or their representatives, including directions of use, advice on side effects, precautions and storage [10]. Counseling enhances patients' adherence to medications and reduces medication-related problems $[10,11]$. Over the years, there has been a gradual transition in pharmacy practice from the traditional roles of the pharmacist such as dispensing to evolving professional roles with more patient-centered care and counseling.

In the current curriculum of the Faculty of Pharmacy at Kuwait University, Kuwait, students are taught about the pharmaceutical care aspects related to different chronic diseases including diabetes. However, in most healthcare settings in Kuwait, pharmacists are mostly practicing traditional services such as dispensing, with minimal patient counseling and education [12]. Even though case studies and practicums in which students dispense simulated prescriptions are used in teaching pharmacy students, a good proportion of student learning about diabetes management and education is still delivered through didactic lectures. Using this mode of teaching, students are passive recipients of knowledge most of the time [13]. This is contrary to the adult learning theories which imply the active involvement of learners in the learning process [14].

Kuwait is one of the countries with a high prevalence of diabetes mellitus among the population $[1,15]$. This workshop was organized to enable final-year pharmacy students at Faculty of Pharmacy, Kuwait University to provide effective counseling on antidiabetic medications for patients with diabetes. Therefore, the objective was to implement a variety of interactive teaching and learning methods in this workshop and to assess their impact on knowledge and self-reported confidence of students in counseling patients about antidiabetic medications.

\section{Subjects and Methods}

A workshop on the role of pharmacists in patient counseling about antidiabetic medications was conducted for all final-year pharmacy students during the academic year 2011-2012. A total of 27 students ( 23 females and 4 males) participated in the workshop. The timeframe of the workshop was 5 hours and it consisted of two main parts (table 1).

\section{Part A: Patient Counseling on the Use of Prefilled Disposable}

Insulin Pen

This part started with an interactive lecture about patient counseling and diabetes education. This was followed by small-group activity, in which the class was divided into five groups each composed of 5-6 students. The groups were asked to discuss the barriers that may affect prefilled insulin pen administration. Then, a video illustrating the administration technique of prefilled insulin pen was viewed. After that, the students were given the opportunity to handle sample devices. Lastly, 2 students were asked to present a role-play scenario on how to provide patient counseling on prefilled insulin pen to the group. At the end of the scene, the 2 students were encouraged to reflect on their performance and feedback was elicited from the group.

\section{Part B: Patient Counseling on Antidiabetic Medications}

This part focused on patient counseling on the different classes of antidiabetic medications, including the oral agents and the injectable glucagon-like peptide-1 (GLP-1) receptor agonists. The first session was an interactive lecture on these medications which covered their clinical pharmacology and main counseling points. During the lecture, the communication skills needed for effective counseling were revised. The students were also instructed to provide comprehensive pharmaceutical care to patients with diabetes, which includes counseling patients on their medications, advising patients on the necessary lifestyle changes and supporting them for self-monitoring of blood glucose. Students were challenged with open-ended questions to enhance active student participation and class discussion during the lecture. Then, a video on the administration technique of the GLP-1 receptor agonists was viewed and the students were allowed to handle sample pens. In the next session, the students were asked to be divided into the same small groups to discuss a case study together. The last session comprised of role-play exercises which were designed to allow the students to practice patient counseling. First, all students were engaged in a dyad role-play to practice counseling on oral antidiabetic agents. Then, 2 students were asked to present a demonstration role-play in which the pharmacist had to counsel the patient regarding the injectable GLP-1 agonist, liraglutide. This was followed by student reflection and provision of feedback from the group.

\section{Student Assessment and Workshop Evaluation}

To assess the impact of the workshop on students' knowledge, attitudes towards diabetes education and confidence in patient counseling about antidiabetic medications, two instruments were 
Table 1. The workshop design

\begin{tabular}{lll}
\hline Time & Activity & Participants \\
\hline 8:00 & Welcome and introduction & Entire class \\
\hline Part A: Patient counseling on the use of prefilled disposable insulin pen & & \\
8:15 & An interactive lecture on diabetes education and the use of prefilled disposable insulin pen & Entire class \\
\hline $8: 45$ & Small-group discussion on the barriers that may affect prefilled disposable insulin pen administration & Small groups ${ }^{\text {a }}$ \\
\hline 9:15 & Demonstration of the proper administration technique of the prefilled disposable insulin pen & Entire class \\
\hline 9:30 & Handling samples of the prefilled disposable insulin pen & Individuals \\
\hline 9:45 & Demonstration role-play on patient counseling on the proper use of the prefilled disposable insulin pen & Entire class \\
\hline $10: 15$ & Coffee break & Entire class \\
\hline Part B: Patient counseling on antidiabetic medications & Entire class \\
\hline $10: 45$ & An interactive lecture on the pharmacology of the antidiabetic medications and their counseling points \\
\hline $11: 15$ & Demonstration of the proper administration technique of the prefilled pen of the GLP-1 receptor agonists & Individuals \\
\hline $11: 30$ & Handling samples of the prefilled pen of the GLP-1 receptor agonists & Small groups \\
\hline $11: 45$ & Case study discussions on the role of pharmacists in the care of patients with diabetes & Pairs of students \\
\hline $12: 15$ & Dyad role-play on patient counseling on oral antidiabetic medications & Entire class \\
\hline $12: 30$ & Demonstration role-play on patient counseling on the use of the prefilled pen of the GLP-1 receptor agonists & Entire class \\
\hline $1: 00$ & Close and debriefing & \\
\hline
\end{tabular}

a Small groups of 5-6 students in each group.

used. First, a knowledge questionnaire which consisted of ten multiple-choice questions was used to assess the knowledge of students about antidiabetic medications before and after the workshop. The validity of the instrument had been previously tested since it had been used to assess the knowledge of a previous cohort of students about antidiabetic medications. Second, another questionnaire was used to assess the attitudes of students towards diabetes education and their confidence in patient counseling about antidiabetic medications. It included statements for which students were asked to indicate their level of agreement on a 5 -point Likert scale $(1=$ strongly disagree, $5=$ strongly agree). This questionnaire was developed after consulting the literature [16-18]. The developed questionnaire was evaluated by the two authors and two visiting professors from the University of Dundee who supervised the workshop. Modifications were made to the questionnaire as needed to enhance its clarity. The final version of the questionnaire had four sections to assess the perceptions of students of their role responsibilities towards diabetes care and education, their perceived ability in communicating with patients, and their perceived ability to provide counseling on antidiabetic medications, as well as to provide education on the administration technique of the injectable medications. To evaluate the workshop, the students were requested to complete an evaluation sheet which included the 5-point Likert scale.

Data were collected anonymously. Pre-/postintervention questionnaires were completed by the students and the difference between their mean responses was compared using SPSS version 17 (Chicago, Ill., USA). Results are presented as means and standard deviations (SD). Paired Student's t test was used to compare the results of pre-/postintervention instruments. Statistical significance was accepted at a $\mathrm{p}$ value of $<0.05$.

Workshop on Patient Counseling about Antidiabetic Medications

\section{Results}

The mean age of the participants was $22.52 \pm 0.935$ years. The mean \pm SD of the pre- and postworkshop knowledge questionnaire scores were $47.9 \pm 17.6 \%$ and $70.7 \pm 18.6 \%$, respectively, and the difference was statistically significant $(\mathrm{p}<0.05)$.

The results of the pre-/postworkshop questionnaires assessing the attitudes of the students towards diabetes education and their confidence in patient counseling about antidiabetic medications are given in table 2 . The overall mean of student responses to the statements about their perceptions of their professional role as pharmacists towards patients with diabetes after the workshop was significantly greater than that prior to the workshop $(\mathrm{p}<0.05)$. Similarly, students perceived their ability to communicate effectively with patients to have improved significantly after the workshop ( $\mathrm{p}<0.05)$. Moreover, the overall mean response of students to the statements measuring their confidence to provide counseling on antidiabetic medications and their ability to educate patients about the proper administration technique of the prefilled pens of insulin and the GLP-1 agonists after the workshop were significantly higher than those before the workshop $(\mathrm{p}<0.001)$. 
Table 2. Results of the pre-/postworkshop questionnaires measuring the attitudes of students towards diabetes education and their confidence in counseling patients about antidiabetic medications $(n=27)$

In general, I believe that ...

Preworkshop Postworkshop p mean $\pm \mathrm{SD}$ mean $\pm \mathrm{SD}$ value

Professional role as pharmacist

... I should involve patients with diabetes in decisions about diabetes care

$\begin{array}{lll}4.59 \pm 0.57 & 4.89 \pm 0.32 & 0.023^{\mathrm{a}}\end{array}$

... pharmacists should help patients with diabetes make informed choices about their care plans

... keeping the blood sugar close to normal can help to prevent the complications of diabetes

... adherence to lifestyle modifications should be reinforced in each counseling session

$4.56 \pm 0.58$

$4.74 \pm 0.45$

0.193

$\begin{array}{lll}4.81 \pm 0.40 & 4.85 \pm 0.36 & 0.721\end{array}$

$4.63 \pm 0.50 \quad 4.74 \pm 0.45 \quad 0.389$

... I should advise patients with diabetes to see another healthcare professional when further assessment and management are needed

$4.33 \pm 0.88 \quad 4.67 \pm 0.62 \quad 0.113$

... I should collaborate with other healthcare professionals to provide self-care information to patients with diabetes

$4.67 \pm 0.48 \quad 4.74 \pm 0.45 \quad 0.560$

$\begin{array}{lll}4.81 \pm 0.40 \quad 4.89 \pm 0.32 & 0.453\end{array}$

... it is important for pharmacists to learn counseling skills

$4.63 \pm 0.58$

$4.79 \pm 0.44$

$0.003^{\mathrm{a}}$

Communication with patients

... I am able to communicate effectively with patients

... I should make patients feel that they can speak freely

$3.81 \pm 0.92 \quad 4.63 \pm 0.49 \quad<0.001^{\mathrm{a}}$

$4.70 \pm 0.47 \quad 4.70 \pm 0.47 \quad 1.000$

Overall mean

$4.26 \pm 0.85$

$4.67 \pm 0.48$

$0.003^{\mathrm{a}}$

Patient counseling on antidiabetic medications

... I have the necessary skills to conduct an interview with patients regarding their prefilled insulin pen

$3.30 \pm 1.07 \quad 4.70 \pm 0.54 \quad<0.001^{\mathrm{a}}$

... I have the necessary skills/knowledge to meet the information needs of patients regarding prefilled insulin pen

$3.33 \pm 1.04 \quad 4.63 \pm 0.49 \quad<0.001^{\mathrm{a}}$

$3.59 \pm 1.01 \quad 4.63 \pm 0.57 \quad<0.001^{\mathrm{a}}$

... I have the necessary skills to conduct an interview with patients regarding antidiabetic drugs

... I have the necessary skills/knowledge to meet the information needs of patients regarding antidiabetic drugs

$3.63 \pm 0.84 \quad 4.59 \pm 0.57 \quad<0.001^{\mathrm{a}}$

... giving patients with diabetes details about the possible side effects of their antidiabetic drugs is important

$4.22 \pm 0.75 \quad 4.67 \pm 0.68 \quad 0.027^{\mathrm{a}}$

Overall mean

$3.61 \pm 0.99 \quad 4.64 \pm 0.57 \quad<0.001^{\mathrm{a}}$

Patient education on the administration technique of the injectable antidiabetic medications

... I am able to administer insulin using prefilled insulin pen

$3.07 \pm 1.24 \quad 4.63 \pm 0.57 \quad<0.001^{\mathrm{a}}$

$3.30 \pm 1.17 \quad 4.81 \pm 0.40 \quad<0.001^{\mathrm{a}}$

$2.52 \pm 0.89 \quad 4.74 \pm 0.45 \quad<0.001^{\mathrm{a}}$

$2.74 \pm 0.90 \quad 4.74 \pm 0.53<0.001^{\mathrm{a}}$

... I am able to administer the prefilled pens of the GLP-1 agonists
... I am able to teach someone else how to administer the prefilled pens of the GLP-1 agonists

$2.74 \pm 0.90$

$4.73 \pm 0.49$

$<0.001^{\mathrm{a}}$

Overall mean

$1=$ Strongly disagree; 2 = disagree; 3 = neutral; 4 = agree; 5 = strongly agree.

a Significant at a $\mathrm{p}$ value $<0.05$.

The results of the workshop evaluation are presented in table 3. Most student responses to the rating categories were 'strongly agree' or 'agree'. All students (100\%) strongly agreed that the workshop was very useful. Case study discussion in small groups was rated as the most preferred learning method by students.

\section{Discussion}

The implementation of a variety of interactive teaching and learning methods in the workshop resulted in improving knowledge and self-reported confidence of students in counseling patients about antidiabetic medica- 
Table 3. Results of the workshop evaluation $(n=27)$

Frequency of response values

\begin{tabular}{lllll}
\hline & 2 & 3 & 4 & 5
\end{tabular}

1. The workshop has helped me understand how to counsel patients with diabetes regarding their therapy

2. After this workshop, I think I can now provide better pharmaceutical care to patients with diabetes

3. I feel more confident in demonstrating the right administration technique of the prefilled pens of the antidiabetic drugs (insulin and GLP-1 agonists)

4. I will be able to use effective communication skills when counseling patients

5. The illustrative materials used in this workshop (e.g. drug samples, videos) were appropriate and they enhanced my learning experience

6. Overall this was a very useful workshop

$1=$ Strongly disagree; 2 = disagree; 3 = neutral; 4 = agree; 5 = strongly agree.
Mean \pm SD

\begin{tabular}{lcccccc} 
& 0 & 0 & 0 & 9 & 18 & $4.67 \pm 0.48$ \\
\hline s) & 0 & 0 & 0 & 7 & 20 & $4.74 \pm 0.45$ \\
& 0 & 0 & 0 & 10 & 17 & $4.63 \pm 0.49$ \\
\hline & 0 & 0 & 0 & 0 & 27 & $5.00 \pm 0.00$ \\
\hline
\end{tabular}

$\begin{array}{lllll}0 & 0 & 9 & 18 & 4.67 \pm 0.48\end{array}$ . 
The limitations of this study include the following: (1) the small number of participants in the workshop, which, although small, represented all final-year students at the Faculty of Pharmacy and (2) the questionnaire used to assess student counseling skills, which featured self-reported skills rather than objectively assessed skills. Additionally, this questionnaire was developed and revised by the authors and did not undergo further validity testing.

\section{Conclusion}

The workshop was successful in improving knowledge and self-reported confidence of pharmacy students in counseling patients about antidiabetic medications at a time when pharmacists are challenged to increase their visibility as healthcare professionals. Educational initiatives which involve engaging teaching methods can be useful in training pharmacy students and pharmacist practitioners on how to provide optimal patient care.

\section{Acknowledgments}

We would like to thank Dasman Diabetes Institute for offering the postgraduate program in diabetes care and education for healthcare professionals in Kuwait in collaboration with Dundee University. We thank all the module leads of the postgraduate program. We are also grateful to our colleagues at the Faculty of Pharmacy, Dr. Abdelmoneim Awad and Dr. Abdullah Al-Bassam, for their support. We thank Professor Mabayoje Oriowo for revising the manuscript.

\section{References}

1 Guariguata L, Whiting D, Weil C, et al: The International Diabetes Federation diabetes atlas methodology for estimating global and national prevalence of diabetes in adults. Diabetes Res Clin Pract 2011;94:322-332.

-2 Brooks AD, Rihani RS, Derus CL: Pharmacist membership in a medical group's diabetes health management program. Am J Health Syst Pharm 2007;64:617-621.

-3 Bratcher CR, Bello E: Traditional or centralized models of diabetes care: the multidisciplinary diabetes team approach. J Fam Pract 2011:S6-S11.

4 Awad A, Dalle H, Enlund H: Diabetic patients' knowledge of therapeutic goals in Kuwait. Med Princ Pract 2011;20:118-123.

5 Campbell RK, Neumiller JJ, White J, et al: Type 2 diabetes: epidemiology and treatment, pathophysiology, new therapeutics, and the evolving role of the pharmacist. J Am Pharm Assoc 2009;49(suppl 1):S2.

6 Ragucci KR, Fermo JD, Wessell AM, et al: Effectiveness of pharmacist-administered diabetes mellitus education and management services. Pharmacotherapy 2005;25:18091816.

7 Kiel PJ, McCord AD: Pharmacist impact on clinical outcomes in a diabetes disease management program via collaborative practice. Ann Pharmacother 2005;39:1828-1832.
8 Berenguer B, La Casa C, de la Matta MJ, et al: Pharmaceutical care: past, present and future. Curr Pharm Des 2004;10:3931-3946.

-9 Lewis RK, Lasack NL, Lambert BL, et al: Patient counseling - a focus on maintenance therapy. Am J Health Syst Pharm 1997;54: 2084-2098, quiz 2125-2126.

10 Palaian S, Prabhu M, Shankar PR: Patient counseling by pharmacist - a focus on chronic illness. Pak J Pharm Sci 2006;19:65-72.

11 Ax F, Branstad JO, Westerlund T: Pharmacy counselling models: a means to improve drug use. J Clin Pharm Ther 2010;35:439-451.

12 Matowe L, Al-Kandery AS, Bihzad SM: Pharmacy in Kuwait. Am J Health Syst Pharm 2003;60:1591-1592.

13 Cantillon P: Teaching large groups. BMJ 2003;326:437-440.

14 Kaufman DM: Applying educational theory in practice. BMJ 2003;326:213-216.

15 Moussa MA, Alsaeid M, Abdella N, et al: Prevalence of type 2 diabetes mellitus among Kuwaiti children and adolescents. Med Princ Pract 2008; 17:270-275.

16 Anderson RM, Fitzgerald JT, Funnell MM, et al: The third version of the Diabetes Attitude Scale. Diabetes Care 1998;21:1403-1407.

17 Delea D, Shrader S, Phillips C: A week-long diabetes simulation for pharmacy students. Am J Pharm Educ 2010;74:130.

18 Taylor J, Smith A: Pharmacy student attitudes to patient education: a longitudinal study. CPJ 2010;143:234-239.
19 Kuhn C, Powell PH, Sterrett JJ: Elective course on medication therapy management services. Am J Pharm Educ 2010;74:40.

20 Jaques D: Teaching small groups. BMJ 2003; 326:492-494.

21 Hartzema AG: Teaching therapeutic reasoning through the case-study approach: adding the probabilistic dimension. Am J Pharm Educ 1994;58:436-440.

22 Lennox L, Devieux J, Huff F, et al: A smallgroup approach to teaching family medicine. Fam Med 1985;17:247-250.

23 Preszler RW: Replacing lecture with peer-led workshops improves student learning. CBE Life Sci Educ 2009;8:182-192.

24 Nestel D, Tierney T: Role-play for medical students learning about communication: guidelines for maximising benefits. BMC Med Educ 2003;7:3-7.

25 Rao D: Skills development using role-play in a first-year pharmacy practice course. Am J Pharm Educ 2011;75:84.

26 Lee AJ, Borham A, Korman NE, et al: Staff development in pharmacist-conducted patient education and counseling. Am J Health Syst Pharm 1998;55:1792-1798.

27 Westberg SM, Bumgardner MA, Brown MC, et al: Impact of an elective diabetes course on student pharmacists' skills and attitudes. Am J Pharm Educ 2010;74:49. 